\title{
ESPORTE INTERATIVO E O DILEMA DE DISTRIBUIÇÃO DE CONTEÚDO: UM ESTUDO DE CASO PARA ENSINO
}

\section{RESUMO}

\author{
${ }^{1}$ Daniela Abrantes Ferreira \\ ${ }^{2}$ Paula Castro Pires de Souza Chimenti
}

Este caso de ensino descreve a trajetória do grupo de mídia brasileiro Esporte Interativo (EI), empresa iniciada por três jovens empreendedores e dedicada a produzir e distribuir conteúdo esportivo em múltiplas plataformas. O dilema está centrado no CEO e sócio fundador do grupo, Edgar Diniz, que enfrenta um novo momento na empresa com a venda iminente para a Turner, braço televisivo do grupo americano Time Warner, no final de 2014. O choque de modelos de negócios pode representar desafios para a gestão da empresa, que precisa decidir os rumos estratégicos futuros, principalmente no que se refere à sua distribuição de conteúdo. As informações utilizadas no caso são reais e foram obtidas através de entrevistas em profundidade com o fundador e CEO da empresa, o outro fundador e Vice-Presidente de Mídias Digitais e o Vice-Presidente de Desenvolvimento de Negócios, além de investigação documental e revisão bibliográfica. Sugere-se que o caso seja utilizado com alunos de pós graduação, em disciplinas de Estratégia Empresarial, com os seguintes objetivos educacionais: a) Análise de ecossistemas de negócios e reconfiguração de indústrias a partir das mudanças geradas pelo desenvolvimento das Tecnologias de Informação e Comunicação; b) Compreensão das questões estratégicas relacionadas à gestão de plataformas e das dinâmicas "winner-takes-all", nas quais as recompensas por se alcançar a liderança são desproporcionais à vantagem que se possui sobre quem não a alcança, típicas de mercados em rede; c) Discussão dos tipos de inovação (incremental e disruptiva) e suas consequências para novos entrantes e incumbentes; d) Planejamento com Cenários.

Palavras-chave: Esporte Interativo; Mídia; Turner; Estratégia; Cenários.

\section{ESPORTE INTERATIVO AND THE CONTENT DISTRIBUTION DILEMMA: A CASE STUDY}

\begin{abstract}
This teaching case describes the trajectory of the Brazilian media group Esporte Interativo (EI), a company started by three young entrepreneurs, and dedicated to produce and distribute sports content in multiple platforms. The dilemma was centered on the CEO and co-founder of the group, Edgar Diniz, who is facing a new phase in the company with the impending sale to Turner, television company owned by Time Warner, in late 2014. The clash of business models may pose challenges to the company's management that must decide the future strategic direction. The information used in the case are real and were obtained through an in-depth interviews with the founder and CEO, the other co-founder and Vice President of Digital Media and the Vice President of Business Development, as well as desk research and literature review. We suggest that the case may be used for postgraduate students in Business Strategy disciplines, with the following educational objectives: a) business ecosystems analysis and reconfiguration of industries from the changes generated by the development of Information and Communication Technologies; b) understanding of strategic issues related to the management platforms and dynamic "winner-takes-all" where the rewards for achieving leadership are disproportionate to the benefit that one has on those who do not reach it, which is typical in networking markets; c) discussion on types of innovation (incremental and disruptive) and consequences for new entrants and incumbents; d) planning with scenarios.
\end{abstract}

Keywords: Esporte Interativo (Interactive Sport); Media; Turner; Strategy; Scenarios.

1 Doutora em Administração pela Universidade Federal do Rio de Janeiro - UFRJ, Brasil.

Professora Adjunta da Faculdade de Administração da Universidade Federal do Rio de Janeiro.

E-mail: danielaabrantes@yahoo.com.br

2 Doutora em Administração pela Universidade Federal do Rio de Janeiro - UFRJ. Brasil.

Professora da Área de Estratégia, Organizações e Sistemas de Informação da Universidade Federal do Rio de Janeiro

E-mail: paula.chimenti@me.com 


\section{ESPORTE INTERATIVO Y EL DILEMA DE DISTRIBUCIÓN DE CONTENIDO: UN ESTUDIO DE CASO}

\section{RESUMEN}

Este caso describe la enseñanza de la trayectoria del grupo de medios de Brasil Esporte Interativo (EI), una empresa iniciada por tres jóvenes empresarios y dedicada a producir y distribuir contenidos deportivos a través de múltiples plataformas. El dilema se centra en el CEO y co-fundador del grupo, Edgar Diniz, frente a un nuevo momento en la empresa con la inminente venta para Turner, el brazo de televisión del grupo estadounidense Time Warner, a finales de 2014. El choque de modelos de negocio puede plantear problemas para la gestión de la empresa, que debe decidir la futura dirección estratégica, particularmente con respecto a la distribución de contenidos. Las informaciónes utilizadas en el caso son reales y se obtuvieron a través de entrevistas con el cofundador y CEO de la compañía, el otro co-fundador y vicepresidente de Medios Digitales y vicepresidente de business development, así como la investigación de documentos y revisión de la literatura. Se sugiere que si se utiliza con estudiantes graduados en disciplinas de estrategia de negocios, con los siguientes objetivos educativos: a) análisis de los ecosistemas de negocios y la reconfiguración de las industrias de los cambios generados por el desarrollo de las Tecnologías de la Información y Comunicación ; b) comprensión de las cuestiones estratégicas relacionadas con las plataformas de gestión y dinámica de "el ganador se lleva todo" en la que los beneficios para lograr el liderazgo son desproporcionados en relación con el beneficio que tiene sobre los que no llegan, mercados típicos de redes; c) La discusión de los tipos de innovación (incrementales y perturbadores) y sus consecuencias para los nuevos operadores y operadores tradicionales; d) La planificación de escenarios.

Palabras clave: Esporte Interativo; Medios de Comunicación; Turner ; Estrategia; Escenarios. 


\section{INTRODUÇÃO}

Era novembro de 2014, e o calor intenso no Rio de Janeiro anunciava que o verão estava próximo. Além do sol forte, uma música entrava pela janela de um escritório no bairro de Botafogo: "The chaaampions... The chaaampions!". Era o hino da Liga dos Campeões da Europa, organizada pela UEFA (União das Federações Europeias de Futebol) ${ }^{i}$, considerada a mais importante competição de clubes de futebol do mundo. Mas, dessa vez, o hino estava sendo cantado por vozes brasileiras.

Edgar Diniz, CEO do grupo de mídia brasileiro Esporte Interativo, ouvia e sorria. Sabia que eram os colaboradores da empresa, que cantavam o hino para comemorar uma grande vitória. Tinham conquistado os direitos exclusivos de transmissão para TV paga e mídias digitais de um dos maiores eventos esportivos do planeta, a Liga dos Campeões da Europa, vencendo gigantes do mercado como ESPN e Globosat, que haviam apresentado proposta conjunta. A empresa estava em festa. Todos sabiam o quanto havia sido difícil sua trajetória até aquele momento: sobreviver e se diferenciar em um mercado tão competitivo quanto o de mídia no Brasil, sem ter o poder financeiro dos grandes competidores.

Edgar sentia um misto de alegria pela vitória e apreensão pelo futuro próximo. A conquista dos direitos da Liga significava também a concretização de um acordo feito meses antes: a venda de $100 \%$ do Esporte Interativo para a Turner, empresa do grupo americano Time Warner, que já detinha $37 \%$ da empresa, fruto de investimento realizado em julho de 2013. Para Edgar, que começara o negócio em 1999 com dois amigos, Leonardo Lenz Cesar e Carlos Moreira, vender a empresa não fora uma decisão fácil. De um negócio dedicado à exibição de eventos esportivos em horários comprados em canais de TV aberta, o Esporte Interativo se tornara um grupo de mídia dedicado a produzir e distribuir conteúdo esportivo em múltiplas plataformas, alcançando mais de 30 milhões de espectadores mensalmente.

Dentro de poucos dias, o EI passaria a ser $100 \%$ da Turner, podendo contar com o poder financeiro de uma grande corporação. Entretanto, Edgar preocupava-se com os efeitos dessa incorporação nas estratégias de sua empresa. O EI destacava-se por ser uma organização ágil e inovadora, que vinha apostando na distribuição de seu conteúdo em diversas plataformas, inclusive via internet TV, com um modelo de distribuição similar ao do Netflix ${ }^{\mathrm{ii}}$ (o chamado over the top, ou OTT). A Turner, por sua vez, tinha seu negócio baseado inteiramente no modelo tradicional de distribuição via TV paga, de onde vinha a maior parte de sua receita.

Edgar sabia que, pelo acordo firmado com a Turner, ele continuaria como principal executivo do Esporte Interativo. Sabia também que ambas as empresas tinham estratégias diferentes no mercado de mídia e conteúdo. E, ainda ouvindo a comemoração de sua equipe, refletia sobre as decisões que teria que tomar num futuro próximo sobre a distribuição de conteúdo do Esporte Interativo. Um caminho possível seria o de aderir integralmente à estratégia de distribuição da Turner, concentrando-se nos modelos tradicionais de rentabilização de conteúdo em vídeo via TV paga. $\mathrm{O}$ outro seria manter a estratégia do EI, incrementando a distribuição em TV paga, mas continuando a apostar no potencial de crescimento das mídias digitais e em novos modelos de negócio. Certamente essa não era a primeira nem a última vez que uma empresa menor, mais ágil e arrojada era incorporada a uma maior, mais tradicional e cautelosa. Para Edgar, esse era o seu momento de decisão.

\section{O INÍCIO}

O Esporte Interativo nasceu como TopSports em 1999, fruto do sonho de três jovens empreendedores: Edgar Diniz, Leonardo Lenz Cesar e Carlos Henrique Moreira Jr., que trabalhavam, respectivamente, no Chase Manhattan Bank, no Bank Boston e na Nike, Inc. O que os unia era a paixão pelo esporte e a ambição de usar a experiência profissional que tinham para criar um modelo de negócios inovador, que potencializasse o esporte como entretenimento no Brasil. Após várias reuniões para discussão e planejamento, os três pediram demissão de seus empregos e investiram, cada um, cerca de $\mathrm{R} \$ 80$ mil no novo negócio.

A princípio, a ideia era atuar junto aos clubes de futebol - esporte mais popular no Brasil desenvolvendo estratégias de marketing e atraindo potenciais investidores. O primeiro grande projeto da empresa foi a organização, em 2001, de um torneio reunindo os maiores clubes de futebol do Nordeste do país: o Campeonato do Nordeste. Os resultados foram excelentes, em termos comerciais e de público.

Porém, trabalhar profissionalizando os campeonatos de futebol no Brasil não se mostrou tarefa fácil. A empresa enfrentou diversos conflitos com dirigentes de Federações Estaduais de futebol e, então, os sócios decidiram que seu negócio não poderia depender dos interesses políticos atrelados ao futebol no Brasil. Começaram, em 2003, a desenvolver o projeto do Esporte Interativo, que em 
síntese era: comprar direitos de transmissão de eventos esportivos importantes no Brasil e no mundo, comprar espaços em TV aberta para poder transmitir esses conteúdos e revolucionar a forma de fazer transmissão esportiva e comercializar patrocínios no Brasil.

Os três sócios compartilhavam a visão de que seria cada vez mais importante que a transmissão de conteúdos esportivos fosse participativa e multimídia, permitindo aos espectadores que se envolvessem e se engajassem. $\mathrm{O}$ projeto estava bem claro no papel e nos sonhos dos três empreendedores. Mas a realidade era bem diferente: eles não tinham ainda o conteúdo (os direitos de transmissão), nem o capital necessário para compra-lo, e tampouco tinham um canal para transmissão. Motivados, começaram a trabalhar em paralelo nas três frentes.

No final de 2003, conseguiram atrair R\$ 4,5 milhões de alguns investidores financeiros, sendo grande parte deles amigos, familiares e colaboradores da empresa. Assim, puderam comprar os direitos de transmissão da Liga dos Campeões da Europa, da NBA (principal liga de basquetebol profissional da América do Norte), da Premier League (Campeonato Inglês de futebol) e do Campeonato Brasileiro de Basquete.

\section{NO AR, ESPORTE INTERATIVO!}

Em janeiro de 2004 o Esporte Interativo fez sua primeira transmissão, em horário comprado na emissora de TV aberta RedeTV. Alinhado com a estratégia do EI de revolucionar as transmissões de conteúdo esportivo no Brasil, os espectadores eram estimulados, através de prêmios, a interagir com as transmissões pela internet e celular. O EI fez o primeiro programa da TV brasileira a ter participação dos espectadores via SMS ${ }^{\text {iii. }}$. Além de proporcionar uma experiência mais interativa, o SMS passou a ser uma fonte de receita para a empresa, que conseguia monitorar a quantidade de pessoas engajadas na sua programação. Isso ajudou bastante a atrair parceiros e anunciantes.

O EI fazia suas transmissões através da compra de horários em TV aberta, inicialmente na Rede TV e posteriormente na Rede Bandeirantes de Televisão (Band). A parceria com a Band funcionou bem, gerando sucesso comercial, de audiência e de engajamento do público, consolidando a participação por SMS e o modelo inovador de comercialização de patrocínio integrado ao conteúdo. Essa experiência bem sucedida com a Band motivou Edgar e seus sócios a sonhar mais alto: queriam o Esporte Interativo 24h no ar.

Em janeiro de 2007, a TopSports lançou o Esporte Interativo 24 horas no ar, para produzir e distribuir conteúdo esportivo em múltiplas plataformas (TV, mídias digitais). A ideia, segundo Edgar Diniz era "estar perto do apaixonado por esportes, onde ele estiver". A partir daí, muitos desafios vieram. Nas palavras de Edgar: "Nos acostumamos a matar um leão por dia”.

A transmissão do EI ocorria principalmente via antena parabólica (Banda C), de onde vinha a maior parte de sua audiência. Entretanto, apesar do alcance de cerca de $40 \%$ dos lares brasileiros, a parabólica não tinha aferição de sua audiência pelo Ibope, tampouco reconhecimento pelo mercado publicitário. Além disso, as principais operadoras de TV paga do país - Net e Sky - fecharam suas portas para o novo canal. Outra grande dificuldade era a falta de fôlego financeiro para competir com os grandes players do mercado na compra dos direitos de eventos esportivos.

Em 2009, a empresa ganhou um aporte financeiro com o investimento de R $\$ 14$ milhões do BNDES, que se tornou dono de $15 \%$ do EI. Com isso, seguiu comprando direitos de transmissão e buscando inovar cada vez mais na forma de apresentá-los a seu público. Ainda em 2009, lançou o Esporte Interativo Móvel, um serviço de conteúdo esportivo via SMS que, em menos de um ano, atingiu a marca de 1,2 milhão de assinantes.

Após sucessos de audiência com a transmissão de eventos esportivos na internet em 2011 e 2012 (inclusive com a primeira transmissão de um jogo de futebol ao vivo pelo Facebook no mundo), o Esporte Interativo continuou inovando. Em 2013, observando os movimentos do mercado e apostando na tendência do espectador de buscar comodidade e customização, a empresa lançou o EI Plus, uma plataforma de conteúdo online que possibilitava ao usuário assistir à programação da emissora 24 horas por dia, ao vivo ou no sistema on demand $^{i v}$. A ideia do EI Plus era permitir que seus usuários assistissem ao conteúdo que escolhessem, a qualquer hora, em qualquer lugar, pelo computador, tablet, smartphone ou Apple TV. O modelo do EI Plus era similar ao do Netflix: o usuário pagava uma mensalidade fixa para ter acesso a toda a plataforma. O EI Plus foi considerado desde seu início um sucesso, nas palavras do VP de mídias digitais, Maurício Portela: "o EI Plus está sempre entre os aplicativos de esportes mais baixadas no iOS e Android e foi escolhido pela Apple para ser o primeiro aplicativo na Apple TV da América Latina."

Em 2013, voltaram a organizar e transmitir a Copa do Nordeste, com a maior média de público no estádio e de audiência na TV do futebol brasileiro no primeiro semestre. Em função desse sucesso, em janeiro de 2014 foi lançado o canal Esporte Interativo Nordeste. A Figura 1 resume os 
lançamentos do Esporte Interativo desde sua fundação.

Figura 1: Lançamentos do Esporte Interativo

\begin{tabular}{|c|l|l|}
\hline Ano & \multicolumn{1}{|c|}{ Lançamento } & \\
\hline 2004 & Esporte Interativo & Transmissão de eventos esportivos \\
\hline 2007 & Canal Esporte Interativo & Canal para 24h de programação esportiva. \\
\hline 2009 & Esporte Interativo Móvel & Serviço de conteúdo esportivo via SMS. \\
\hline 2013 & EI Plus & $\begin{array}{l}\text { Plataforma de conteúdo online com a } \\
\text { programação da emissora 24 horas por dia, ao } \\
\text { vivo ou no sistema on demand. }\end{array}$ \\
\hline 2014 & Canal Esporte Interativo Nordeste & $\begin{array}{l}\text { Canal para TV paga para transmissão de todas as } \\
\text { partidas da Copa do Nordeste }\end{array}$ \\
\hline
\end{tabular}

Fonte: Elaboração Própria.

\section{A INDÚSTRIA DE MÍDIA NO BRASIL}

O cenário da indústria de mídia no Brasil em 2014 era bastante desafiador. O mundo vinha atravessando mudanças cada vez mais radicais, em intervalos de tempo cada vez menores, resultando em forte instabilidade para o ambiente de negócios como um todo. A velocidade crescente dessas mudanças era, em grande parte, fruto do surgimento de novas tecnologias, que tornavam o mundo mais digital, pessoal, virtual e móvel.

A velocidade dessas mudanças na década iniciada em 2010 era especialmente evidente no ecossistema das mídias. Rapidamente, blogs, redes sociais, sites, videogames e celulares, algumas das chamadas "mídias emergentes", vinham ganhando relevância em relação aos meios tradicionais. No Brasil, a TV aberta, detentora de $61 \%$ de participação na verba publicitária do setor de mídias em 2010 (Projeto Intermeios, 2011), também dava sinais de mudança: apesar de receber investimentos crescentes dos anunciantes, alguns programas populares do horário nobre vinham registrado queda em seus índices de audiência (Media Book, 2012).

Em paralelo, as novas mídias digitais ${ }^{\mathrm{v}}$ experimentavam uma expansão acentuada no mercado brasileiro. Entre 2008 e 2010, enquanto o investimento publicitário em internet cresceu cerca de $60 \%$, o mercado total de mídia cresceu $22 \%$. Do lado dos consumidores, ficava evidente a popularização de dispositivos digitais: no mesmo biênio de 2008/2010, o número de domicílios com celulares, computadores de mesa, videogames e notebooks cresceu 16\%, 34\%, 38\% e 166\%, respectivamente. Em 2010, enquanto $98 \%$ dos domicílios contavam com ao menos um aparelho de $\mathrm{TV}, 84 \%$ contavam com ao menos um celular (Projeto Intermeios, 2011).

Entre 2009 e 2010, em especial, o ambiente de negócios das mídias passou por grandes mudanças. Plataformas como iOS e
Android se popularizaram e, com elas, o conceito de aplicativos $^{\mathrm{vi}}$ se consolidou. Em 2010, surgiram novas classes de dispositivos, como os tablets, cujas vendas se tornaram tão ou mais pujantes quanto a de PCs num intervalo de tempo inferior a dois anos, fazendo o consumo de mídia ainda mais móvel e ubíquo. No mesmo período, a rede social Facebook se consolidou como a quarta maior fonte de tráfego para sites de notícias, enquanto o paywall do New York Times (cobrança de uma taxa fixa para acesso a conteúdo digital) mostrou como veículos tradicionalmente adeptos de modelos de negócio baseados no subsídio cruzado ${ }^{\text {vii }}$ passaram a cobrar diretamente dos consumidores pelo seu conteúdo. Inversamente, indústrias partidárias da cobrança por conteúdo, como a de games, passaram a trabalhar de forma crescente com modelos de negócio baseados na distribuição gratuita de versões dos seus produtos.

Apesar das mudanças recentes, em 2014 a hegemonia da TV aberta no país permanecia, tanto do ponto de vista da audiência quanto do mercado publicitário, com a maior participação na geração de receitas do setor de mídia brasileiro. Seu modelo de negócios era calcado na receita publicitária, isto é, na venda de espaço para anunciantes. Os principais players de TV aberta no Brasil eram: Rede Globo, Rede Record, SBT, Rede Bandeirantes e Rede TV. A Rede Globo vinha ocupando a posição de liderança nesse mercado havia mais de 25 anos, mas as emissoras Record e SBT vinham ameaçando essa liderança.

No Brasil, as primeiras transmissões efetivas de TV paga começaram nos anos 1980, com a CNN trazendo notícias 24 horas por dia, e a MTV transmitindo videoclipes musicais. Funcionavam num processo normal de radiodifusão, transmitindo em UHF, com canal fechado e codificado. Tais serviços foram $o$ embrião para a implantação do serviço de TV por 
assinatura. Em 1991, grandes grupos de comunicação ingressaram no setor. As Organizações Globo criaram a GloboSat com um serviço de TV paga via satélite, e o Grupo Abril criou a TVA. Outros grupos importantes, como a RBS e o Grupo Algar, ingressaram no mercado logo em seguida. A TV paga obteve um crescimento expressivo, atingindo quase $30 \%$ dos domicílios brasileiros em 2014 (Agência Brasil, 2014).

A Tabela 1 e a Figura 2 apresentam um resumo do desempenho de cada meio da indústria em 2014. Pode-se observar que a mídia impressa (revistas e jornais) vinha perdendo espaço na geração de receita publicitária, enquanto TV aberta, TV paga e Internet cresciam muito em participação no bolo publicitário.

Tabela 1: Desempenho dos meios no total da receita publicitária brasileira em 2014

\begin{tabular}{|l|c|c|c|}
\hline & $\begin{array}{c}\text { Faturamento } \\
\mathrm{R} \$\end{array}$ & $\begin{array}{c}\text { Variação em relação } \\
\text { a 2013 }\end{array}$ & Participação no total \\
\hline TV aberta & 11.912 .505 .802 & $+22,09 \%$ & $68,91 \%$ \\
\hline Jornal & 1.486 .727 .784 & $-6,54 \%$ & $8,60 \%$ \\
\hline TV paga & 926.309 .882 & $+48,98 \%$ & $5,36 \%$ \\
\hline Internet & 776.256 .906 & $+23,75 \%$ & $4,49 \%$ \\
\hline Revista & 721.532 .756 & $-8,62 \%$ & $4,17 \%$ \\
\hline Rádio & 688.713 .364 & $+12,35 \%$ & $3,98 \%$ \\
\hline $\begin{array}{l}\text { Mídia exterior (outdoor, } \\
\text { mobiliário urbano etc) }\end{array}$ & 663.099 .939 & $+35,91 \%$ & $3,84 \%$ \\
\hline Guias e Listas & 60.386 .903 & $-35,59 \%$ & $0,35 \%$ \\
\hline Cinema & 52.412 .326 & $+9,23 \%$ & $0,30 \%$ \\
\hline
\end{tabular}

Fonte: Projeto Intermeios, 2014.

Figura 2: Desempenho dos meios no total da receita publicitária brasileira em 2014 (Total R\$ 17,3 bilhões)

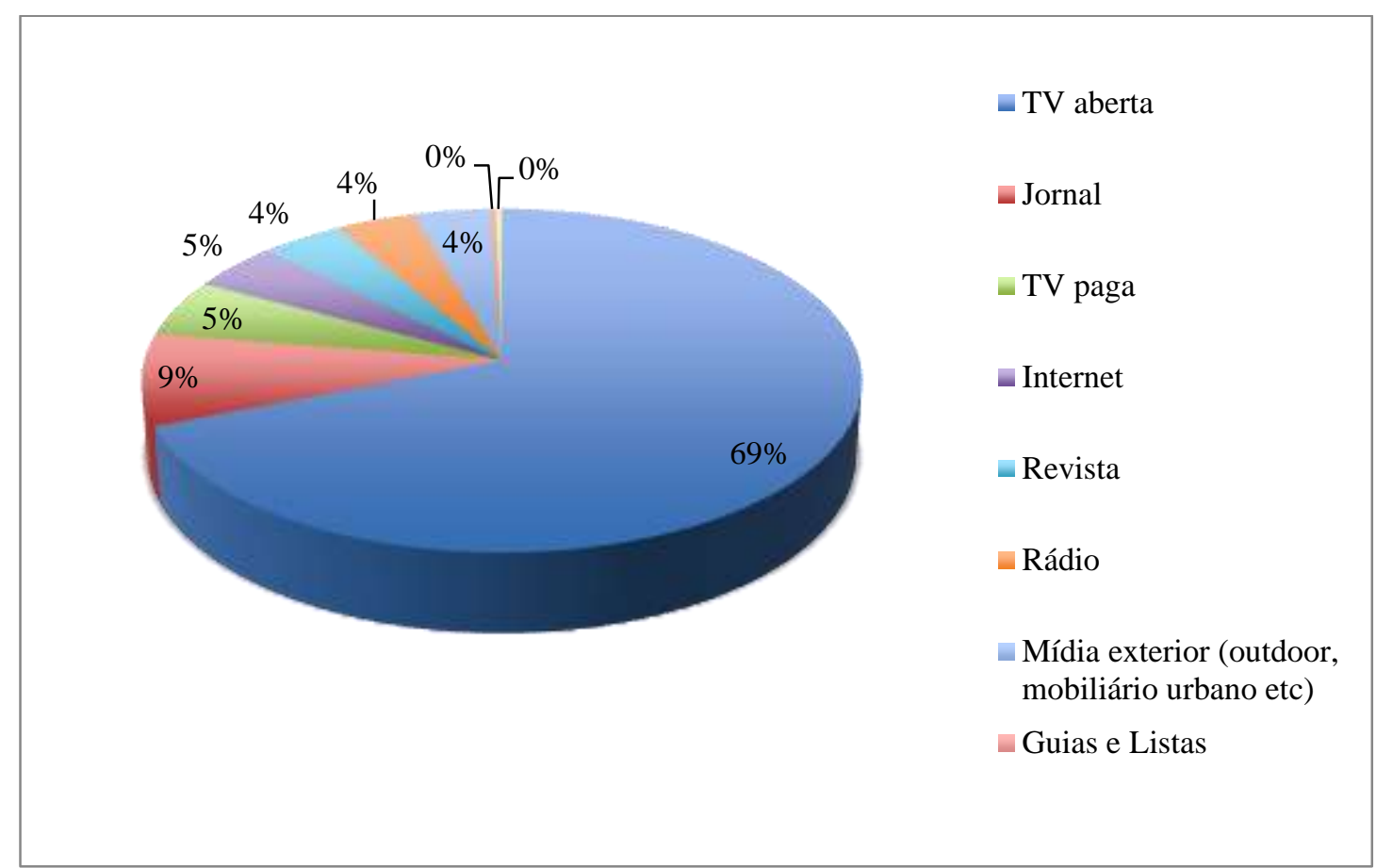

Fonte: Projeto Intermeios, 2014.

No que se refere ao conteúdo esportivo oferecido na TV paga, três grandes players se destacavam: SporTV (GloboSat), ESPN Brasil (ESPN/Disney) e Fox Sports (Fox). Ou seja, a competição nesse mercado incluía, respectivamente, o maior grupo de mídia do Brasil, o maior canal de esportes do mundo e um dos maiores grupos de mídia do mundo. Todos eram 
oferecidos pelas principais operadoras de TV a cabo do país - Net e Sky. O processo de entrada da Fox Sports na grade dessas operadoras, em 2012, foi conturbado. A Fox havia adquirido os direitos exclusivos de transmissão da Copa Libertadores da América na TV paga, e anunciou que iria transmitir essa competição apenas em seu novo canal, Fox Sports. Houve então uma grande pressão dos clientes das operadoras para que estas incluíssem o novo canal em sua grade. A estratégia funcionou, e o Fox Sports passou a fazer parte da grade de programação da Net e da Sky.

Com o crescimento da concorrência nos canais dedicados a conteúdos esportivos na TV paga, a briga pelos direitos de transmissão das principais competições esportivas se tornou mais acirrada, resultando em um aumento exponencial do valor desses direitos. Cada vez mais, o mercado de produção e transmissão de conteúdo esportivo no Brasil mostrava-se pouco favorável a empresas sem um grande fôlego financeiro.

\section{A TURNER ENTRA NO JOGO}

Em 2013, o Esporte Interativo era líder de audiência entre os canais de esportes na TV no Brasil, com alcance mensal de aproximadamente 33 milhões de telespectadores únicos. No mundo digital, firmava-se como o veículo esportivo número um nas redes sociais, tendo conquistado quase 10 milhões de fãs no Facebook no fim de 2014, além de centenas de milhares de seguidores no Twitter, no Instagram e no canal do EI no YouTube.

Porém, a distribuição continuava sendo um grade desafio, bem como a capacidade financeira para compra dos direitos de eventos esportivos, cada vez mais valorizados. Ficava bastante claro para Edgar que a empresa precisava de um parceiro à altura dos grandes concorrentes do mercado. Depois de inúmeras discussões junto ao Conselho de Administração da empresa, ficou decidido que o EI buscaria um parceiro que não apenas desse suporte financeiro ao negócio, mas também estratégico.

Começaram, então, a dialogar com alguns possíveis interessados - grupos de mídia do Brasil e do exterior. Assessorado pela Goldman Sachs, o EI fechou um acordo de investimento com a Turner Broadcasting, uma das maiores empresas globais de programação de TV paga, do grupo de mídia americano Time Warner, com receita líquida de mais de US\$ 30 bilhões. A Turner viu no Esporte Interativo uma oportunidade de investir em um canal com conteúdo esportivo, algo que ainda não possuía em seu portfólio, e o esporte tornava-se cada vez mais um conteúdo estratégico no Brasil e no mundo. Assim, em 2013, a Turner comprou 37\% do EI, em um aporte de R\$ 80 milhões, inteiramente usado pra investimento na companhia. O controle da empresa continuou nas mãos de seus sócios controladores, e a Turner passou a ocupar duas das sete cadeiras do Conselho de Administração. $\mathrm{O}$ fato foi amplamente noticiado na imprensa brasileira. Em uma dessas reportagens, Alex González, vice-presidente de desenvolvimento corporativo e novas mídias da Turner na América Latina, declarou: "A TV paga no Brasil vem crescendo e o país terá grandes eventos esportivos nos próximos anos. É um mercado no qual queremos investir".

Edgar também se mostrava animado, e declarou à época: "A entrada da Turner ampliará significativamente nossa capacidade de investimento e nos dará acesso ao 'estado da arte' em produção de conteúdo. Além disso, possibilitará a exploração de novos modelos de negócios nesse ambiente dinâmico de distribuição de conteúdo em múltiplas plataformas. O tamanho do nosso sonho acaba de crescer enormemente". A declaração de Juan Carlos Urdaneta, presidente da Turner Latin America, reforçava o espírito da parceria: "Esse investimento no EI sinaliza um importante passo estratégico para a Turner no Brasil, nosso maior mercado na América Latina".

Além dos R\$ 80 milhões da Turner, o EI conseguiu levantar mais R\$ 7 milhões com seus outros sócios. Os recursos seriam usados para comprar direitos de transmissão de eventos esportivos, investir na produção em alta definição (HD) e no desenvolvimento de novos formatos de programas e distribuição de conteúdo. Edgar define assim sua visão na época: "Precisávamos acelerar o crescimento da empresa para permanecermos competitivos em um mercado de gigantes".

\section{MISSÃO, VISÃO E ESTRUTURA DO ESPORTE INTERATIVO}

Estruturado como uma empresa de mídia multiplataforma, o Esporte Interativo caracterizavase por usar uma linguagem descontraída e carregada de emoção em suas transmissões. Tinha como missão "conectar, entreter e transformar as pessoas através da emoção do esporte", e sua visão era "ser a plataforma de esportes dominante em todas as mídias no Brasil".

Em 2014, o Esporte Interativo contava com cerca de 350 funcionários distribuídos em seus escritórios no Rio e em São Paulo. A Figura 3 apresenta o organograma da empresa. A estrutura acionária do EI, apresentada na Figura 4, mostra o controle nas mãos da empresa TopsSports Holding, cujo controle era dos principais executivos do EI (incluindo seus fundadores). 


\section{Figura 3: Organograma do Esporte Interativo}

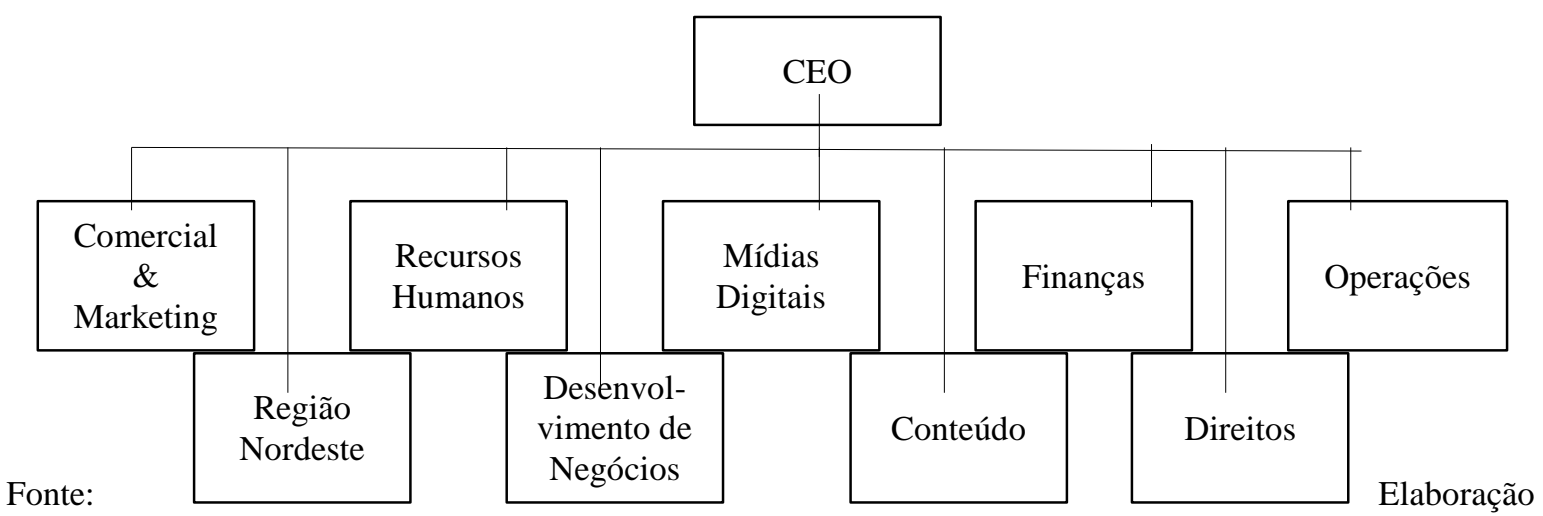

Própria.

Figura 4: Estrutura Acionária do Esporte Interativo em 2014

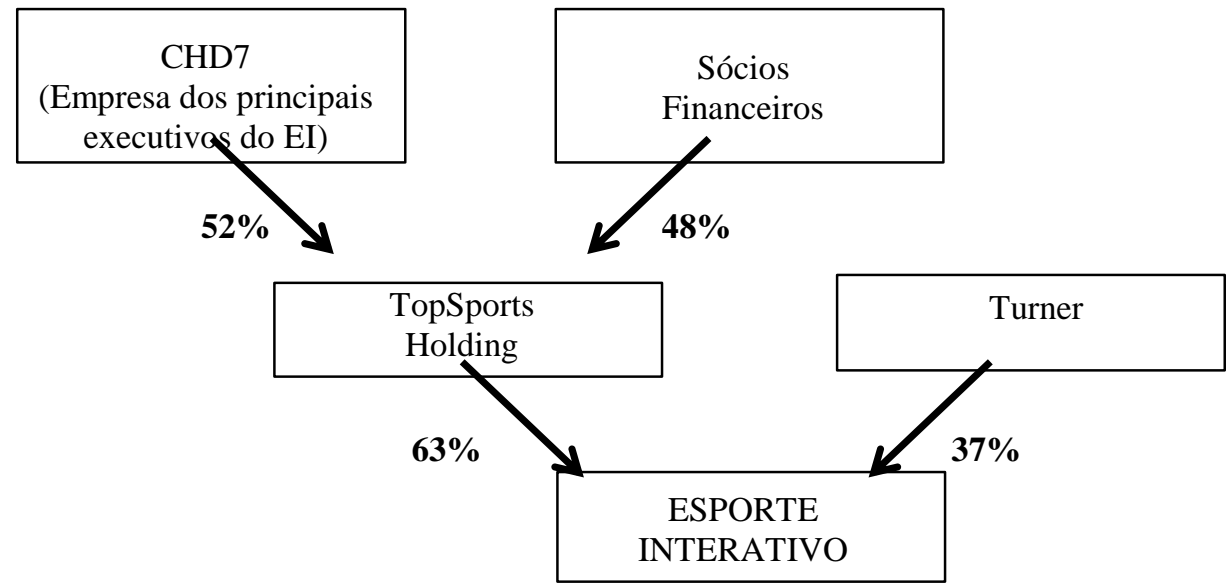

Fonte: Elaboração Própria.

\section{O GOL DE PLACA}

Em 2014, já com o aporte de capital advindo da venda de parte da empresa para a Turner, o Esporte Interativo preparava-se para participar da concorrência para compra dos direitos de futebol tidos como os mais importantes do mundo depois da Copa do Mundo: a Liga dos Campeões da Europa. Edgar acreditava que ganhar essa concorrência era fundamental para a empresa: se o EI conseguisse os direitos exclusivos dessa competição, isso poderia quebrar a resistência das principais operadoras de TV paga do país, Net e Sky. A pressão do público seria grande, analogamente ao que havia acontecido quando a Fox Sports foi lançada no Brasil detendo os direitos exclusivos de transmissão da Copa Libertadores da América.

Ao longo dos últimos 20 anos, a ESPN foi a detentora exclusiva dos direitos de TV paga da Liga dos Campeões, e entrou na concorrência ao lado do Sportv, canal do Grupo Globo, o maior grupo de mídia do país. As duas emissoras fizeram uma parceria para dividir os direitos e formalizaram uma proposta à UEFA. No entanto, o Esporte Interativo conseguiu fazer a maior oferta e ganhou a concorrência, adquirindo os direitos exclusivos de transmissão de todos os jogos da competição das temporadas 2015/2016, 2016/2017 e 2017/2018 para TV paga e mídias digitais. O valor acertado ultrapassou 100 milhões de dólares, pelas 3 temporadas.

A TV Globo ganhou a concorrência da TV aberta, mas sem o direito de transmitir todas as partidas. Sendo assim, o Esporte Interativo, que não estava na grade das maiores operadoras de TV paga do país, passou a ser o único canal a transmitir todos os jogos da Liga dos Campeões da Europa durante as três temporadas seguintes. Conforme previsto, a pressão do público do Esporte Interativo pela entrada do canal na Net e na Sky se acirrou, 
sobretudo nas páginas das empresas nas redes sociais.

Fazer a oferta vencedora pelos direitos da Liga dos Campeões da Europa, em um montante total de centenas de milhões de reais, só foi possível devido a um acordo estabelecido entre Esporte Interativo e Turner. A partir do momento em que a concorrência foi ganha, os advogados de ambas as empresas começaram a desenhar o contrato de venda de $100 \%$ do EI para a Turner.

\section{Na Marca do Pênalti: Em que Canto Bater?}

O Esporte Interativo cresceu dentro de um mercado complexo e difícil, tendo apostado desde o início na inovação e em novas formas de distribuir seu conteúdo. Naquela tarde de novembro de 2014, Edgar refletia sobre o futuro da empresa, da qual em breve deixaria de ser sócio controlador para ficar apenas no papel de executivo. Tinha profundo conhecimento da empresa que ajudara a criar e do mercado em que atuava, mas ainda estava se familiarizando com a engrenagem da Turner. Sabia que, historicamente, a Turner tendia a fazer uma integração vertical das empresas que adquiria e, possivelmente, esse seria o caminho a ser implementado no Esporte Interativo. Parecia-lhe que, passando a ser um dos canais da Turner - ao lado de Cartoon Network (líder de TV paga no Brasil), TNT, CNN Internacional etc. - o EI teria a negociação para inseri-lo na grade das operadoras de TV paga Net e Sky facilitadas. Para Leonardo Cesar, co-fundador do EI e Vice-Presidente de Desenvolvimento de Negócios, o momento era de vencer desafios e aproveitar as oportunidades: “Tínhamos pela frente o desafio de realizar que não éramos mais empreendedores. Por outro lado, passar a fazer parte de um grupo muito maior nos dava a oportunidade de levar o nosso negócio para um outro nível de tamanho e capacidade competitiva, o que possibilitaria ao EI crescer ainda mais e poder disputar em alto nível o jogo de esporte no Brasil."

Para Edgar, a grande força do EI estava na sua agilidade para responder e até se antecipar às mudanças do mercado, lutando para superar suas fraquezas com uma busca constante de inovação. Mas, a partir daquele momento, como parte de uma engrenagem muito maior que tinha estratégias diferentes, que caminho seguir? Apostar nos novos modelos, acreditando que os consumidores buscarão, cada vez mais, conveniência e poder de escolha? Ou priorizar a distribuição via TV paga, alinhando-se à estratégia da Turner no Brasil? Para tornar o desafio ainda mais complexo, investir em internet $\mathrm{TV}$, com conteúdos over the top, significava entrar em conflito com as principais operadoras de TV paga no Brasil, NET e Sky. Essa não era uma decisão para se tomar sozinho, e nem de um dia para o outro. Mas Edgar sabia que, assim que a venda para a Turner fosse concretizada, ele e a equipe da alta gestão do Esporte Interativo teriam que se posicionar sobre que estratégias seguir.

\section{NOTAS DE ENSINO}

\section{Fontes dos Dados}

As informações contidas neste caso são reais e foram obtidas através de três diferentes meios: entrevistas em profundidade, investigação documental e revisão bibliográfica. Primeiramente, foram realizadas entrevistas com roteiro semiestruturado com três executivos da empresa: o fundador e CEO, Edgar Diniz; o fundador e VicePresidente de Desenvolvimento de Negócios, Leonardo Lenz Cesar; e o Vice-Presidente de Mídias Digitais, Maurício Portela. As entrevistas tiveram duração de cerca de duas horas cada, e visaram à obtenção de informações que permitissem compreender o histórico da empresa, as dificuldades e oportunidades encontradas desde seu lançamento até o momento do dilema do caso, e os desafios vislumbrados para o futuro. A análise da narrativa dos executivos permitiu uma descrição mais fidedigna do caso (cf. Isabella, 1990). Foram também analisadas informações presentes no site e em documentos da empresa, e em sites de veículos de comunicação. Essas pesquisas adicionais favoreceram o cruzamento com as informações obtidas nas entrevistas, contribuindo para tornar a descrição do caso mais completa e realista (cf. Gil, 1999). A estrutura do caso e das notas de ensino seguiu as recomendações de Roesch (2006).

\section{Objetivos de Aprendizagem}

Este caso foi elaborado para ser usado em disciplinas de Estratégia Empresarial, sendo desejável que os participantes já tenham sido expostos anteriormente aos conceitos fundamentais de estratégia. O caso é especialmente adequado para aulas sobre gestão estratégica de inovação, contribuindo para discussão e solidificação de conceitos relativos à Gestão de Inovação (Day, Schoemaker e Gunther, 2000; Christensen, 1997; Christensen, Johnson e Rigby, 2002; Garvin e Levesque, 2005), e Gestão Estratégica de Mercados em Rede e Plataformas (Eisenmann, Parker e Van Alstyne, 2006; Eisenmann, 2006; Iyer, Lee e Venkatraman, 2006; Adner, 2006).

O objetivo geral da aplicação de um caso de ensino é desenvolver nos participantes a capacidade analítica, de argumentação e de tomada de decisão (Mauffette-Leenders, Erskine, \& Leenders, 1997), visto que o método possibilita um envolvimento mais ativo do aluno no processo de 
ensino-aprendizagem. O caso Esporte Interativo oferece um exemplo de dilema relacionado à estratégia de uma empresa de médio porte que está

- Análise de ecossistemas de negócios e reconfiguração de indústrias a partir das mudanças geradas pelo desenvolvimento das Tecnologias de Informação e Comunicação (Iyer, Lee e Venkatraman, 2006; Adner, 2006; Iansiti e Levien, 2004)

- Compreensão das questões estratégicas relacionadas à gestão de plataformas e das dinâmicas "winnertakes-all", onde as recompensas por se alcançar a liderança são desproporcionais à vantagem que se

\section{Questões para Discussão}

1) Quais são os fatores que levaram o Esporte Interativo a alcançar posição de liderança no mercado de mídia brasileiro até o momento do dilema do caso?

2) Quais são os principais concorrentes do Esporte Interativo? Faça uma análise da dinâmica da indústria em que a empresa está inserida.

3) Quais são os principais desafios para o Esporte Interativo perseguir sua estratégia inovadora dentro do novo contexto?

4) No lugar de Edgar, o que você faria para preparar a empresa para o futuro, considerando a análise feita sobre a dinâmica da indústria e a venda iminente para a Turner?

\section{ANÁLISE DO CASO}

O professor pode iniciar a discussão do caso estimulando os alunos a refletirem sobre a plataforma Esporte Interativo e EI Plus. O desenho da plataforma e dos principais stakeholders da empresa permite a compreensão dos efeitos de rede (Eisenmann, 2006) e das oportunidades de modelos de negócio (contrastando as formas tradicionais de obtenção de receitas e aferição de resultados nas mídias com os modelos emergentes e disruptivos). Para Eisenmann (2006), a plataforma compreende os componentes e regras comuns empregados pelos usuários das redes (incluindo consumidores e complementares), na maioria das suas interações. Enquanto os componentes incluem hardware, software, serviços e arquitetura, as regras se referem aos padrões que asseguram a para ser comprada por um gigante do setor em que atua. Especificamente para esse caso, são sugeridos os seguintes objetivos educacionais:

- possui sobre quem não a alcança, típicas de mercados em rede (Eisenmann, Parker e Van Alstyne, 2006; Eisenmann, 2006).

- Discussão dos tipos de inovação (incremental e disruptiva) e suas consequências para novos entrantes e incumbentes (Day, Schoemaker e Gunther, 2000; Christensen, 1997; Christensen, Johnson e Rigby, 2002).

- Planejamento Estratégico com Cenários (Day, Schoemaker e Gunther, 2000; Schoemaker, 1995; Garvin e Levesque, 2005).

compatibilidade técnica entre componentes, aos protocolos, políticas e contratos.

Outra questão importante a ser abordada é a gestão de inovação e os tipos de inovação. É possível a partir da análise do ecossistema destacar as diferentes relações que os diversos participantes do ecossistema tem com a inovação, utilizando os conceitos trabalhados por Christensen (1997) e Day et al (2000). As mudanças recentes no mundo dos negócios, com uma conexão cada vez maior das empresas e a necessidade de trabalhar as redes e enxergar setores como ecossistemas podem ser destacadas. Muitas inovações disruptivas não sobrevivem ao isolamento, pois necessitam de complementares para que suas ofertas atraiam os consumidores. Iyer, Lee e Venkatraman (2006), assim como Adner (2006) e Iansiti e Levien (2004), propõem o desenho de um ecossistema de negócios como uma ferramenta estratégica, que permite aos gerentes examinar o papel da sua empresa e de outros concorrentes e complementares neste sistema complexo.

A questão é que não se trata mais de apenas gerenciar complementares, mas sim de lidar com uma intricada e mutante rede de cooperação e competição, na qual alianças e troca de informações garantem a interoperabilidade e empresas se aliam a competidores em determinados negócios, enquanto permanecem "inimigos" em outros. Iyer, Lee e Venkatraman (2006) propõem este gerenciamento como o de um ecossistema, um "pequeno mundo" no qual todos os players se relacionam em poucos graus de separação. Neste contexto, as empresas precisam desenhar e compreender o ecossistema no qual estão inseridas, calibrar a sua rede de relacionamentos, examinar os papéis centrais na 
rede e planejar como explorar os recursos da rede, utilizando um scorecard da rede.

A análise do ecossistema no qual o Esporte Interativo está inserido reflete os focos de criação e destruição de valor que a relação entre o atual modelo de negócios da empresa e seu ambiente promove. Chama a atenção a força que os proprietários dos direitos de transmissão detêm neste meio, posto que se apresentam como hubs, isto é, pontos focais da rede, à medida em que diversos players dependem de sua concessão para entregar valor ao consumidor final. $\mathrm{O}$ Esporte Interativo, em especial, situa-se em posição de grande dependência junto a este $h u b$, visto que grande parte de sua oferta está sujeita ao bom relacionamento com o mesmo.

Após o desenho da plataforma e do ecossistema, a discussão pode avançar para o futuro da empresa. Aqui, uma abordagem possível é a utilização do planejamento com cenários (Schoemaker, 1995; Garvin e Levesque, 2005). O planejamento de cenários é um método para imaginar futuros possíveis e simplificar a avalanche de dados sobre uma empresa em um número fixo de estados possíveis. A ideia não é cobrir todas as possibilidades, mas circunscrevê-las, eliminando os dois erros mais comuns no processo decisório: superestimar ou subestimar mudanças. O método compreende a identificação das tendências e incertezas relativas a um negócio e a combinação destas em um número limitado de opções de futuro possíveis. Este processo, além de ampliar a visão de futuro dos empresários e evitar as "adivinhações" quanto ao futuro, permite a identificação das competências necessárias para uma empresa

\section{Tendências:}

- Convergência digital, como dispositivos multitasking viii e conteúdos em múltiplas plataformas de mídia.

- Maior oferta de conteúdo e capacidade de transmissão de dados.

- Mobilidade, com a mídia chegando ao consumidor $24 \mathrm{~h}$ por dia, 7 dias por semana.

Incertezas:

- Regulamentação dos Direitos - hoje, a venda dos direitos segue um padrão no qual o detentor disponibiliza para um único player os direitos de TV, web e mobile. Entretanto, isso pode ser modificado até um extremo em que os direitos são negociados um a um.

- TV Aberta ou IPTV - com tantas opções de conteúdo e tecnologias, fica difícil definir quanto tempo os consumidores irão dedicar a cada mídia. Não se sabe quais são os reais impactos da mobilidade e acesso em grande escala à internet, se isso irá modificar o competir no futuro. O objetivo é desenvolver as competências que serão efetivas para múltiplos segmentos em diferentes cenários.

Outra aplicação estratégica do planejamento de cenários é o gerenciamento de opções reais, descrito por Day, Schoemaker e Gunther (2006). No âmbito financeiro, opções criam a oportunidade, mas não a obrigação, de realizar um investimento futuro. Da mesma forma, as opções reais são aplicadas a investimentos em tecnologias emergentes, criando a possibilidade estratégica de utilizar uma determinada tecnologia no futuro, sem, entretanto, representar um comprometimento pleno no momento atual. Mantendo a analogia com o mercado financeiro, o "preço" da opção é o custo de desenvolvimento ou aquisição da nova tecnologia, "exercer" a opção significa decidir comercializar a nova tecnologia, e o "preço de exercício" é o custo envolvido no lançamento e comercialização da nova tecnologia.

Assim, com o objetivo de melhor entender a configuração da indústria em estudo e as possibilidades futuras para o Esporte Interativo, o professor deve encorajar os alunos a pesquisar previamente as principais tendências e incertezas que podem gerar forte impacto nas empresas que atuam no setor. Sugere-se como fontes para se buscar essas informações: Agência Brasil (2014), Media Book (2012), Projeto Intermeios (2014) referências que estão detalhadas ao final do artigo. A seguir, um resumo de algumas tendências e incertezas e de como se pode combina-las na elaboração de cenários futuros.

- Customização e fortalecimento do consumidor.

- Conteúdo gerado pelo consumidor.

- Redes sociais cada vez mais fortes e presentes.

- Interatividade.

- Propaganda cada vez mais integrada ao conteúdo.

comportamento dos consumidores frente a uma tela de TV tradicional ou até que ponto as novas mídias irão substituir as tradicionais em sua preferência.

- $\quad$ Privacidade, propaganda e conteúdo pago - A relação entre as TVs Abertas e os anunciantes se mantém sustentável porque, até muito recentemente, a única forma conhecida de se fazer propaganda era colocando o consumidor de forma passiva frente ao veículo e o submetendo ao turbilhão de informações que se desejasse transmitir. Com o advento da internet e de novas tecnologias que permitem a 
interatividade, surge a possibilidade de este mesmo consumidor passar a ter um papel ativo na relação com as empresas. As inovações que têm ocorrido nas telecomunicações viabilizam a criação de propagandas interativas e personalizadas, mais sofisticadas e adaptadas aos meios. Entretanto, a contrapartida disto é a liberação de uma quantidade relevante de informações pessoais a empresas como Google ou Apple. Não se sabe ainda qual o nível de privacidade desejado ou qual o mínimo aceitável para os indivíduos. O que se deseja saber é se o modelo de subsídio cruzado evoluirá para formas cada vez mais elaboradas de propaganda personalizada, ubíqua e relevante, ou se será substituído por outro em que o consumidor paga exatamente por aquilo que deseja assistir.

A partir da discussão acerca das informações sobre as tendências e incertezas da indústria, pode- se estimular os alunos a construir cenários. A construção de cenários ocorre com a combinação de incertezas-chave, a fim de encontrar situações futuras onde uma indústria e uma empresa podem se encontrar futuramente. Como exemplo, foram criados aqui cenários na indústria de TV no Brasil em um horizonte de tempo de cinco anos.

As incertezas escolhidas foram o tipo de propaganda que terá mais valor (tradicional ou personalizada e interativa) e o meio no qual o conteúdo chega a seu cliente (broadband transmissão de dados via banda larga com capacidade para transportar simultaneamente vários tipos de tráfego e sinais ou broadcast - forma de transmissão utilizada pela TV aberta, em que a mesma informação é enviada para muitos receptores ao mesmo tempo). A partir disso, quatro cenários foram vislumbrados

\section{Figura 1 da Nota de Ensino: Cenários}

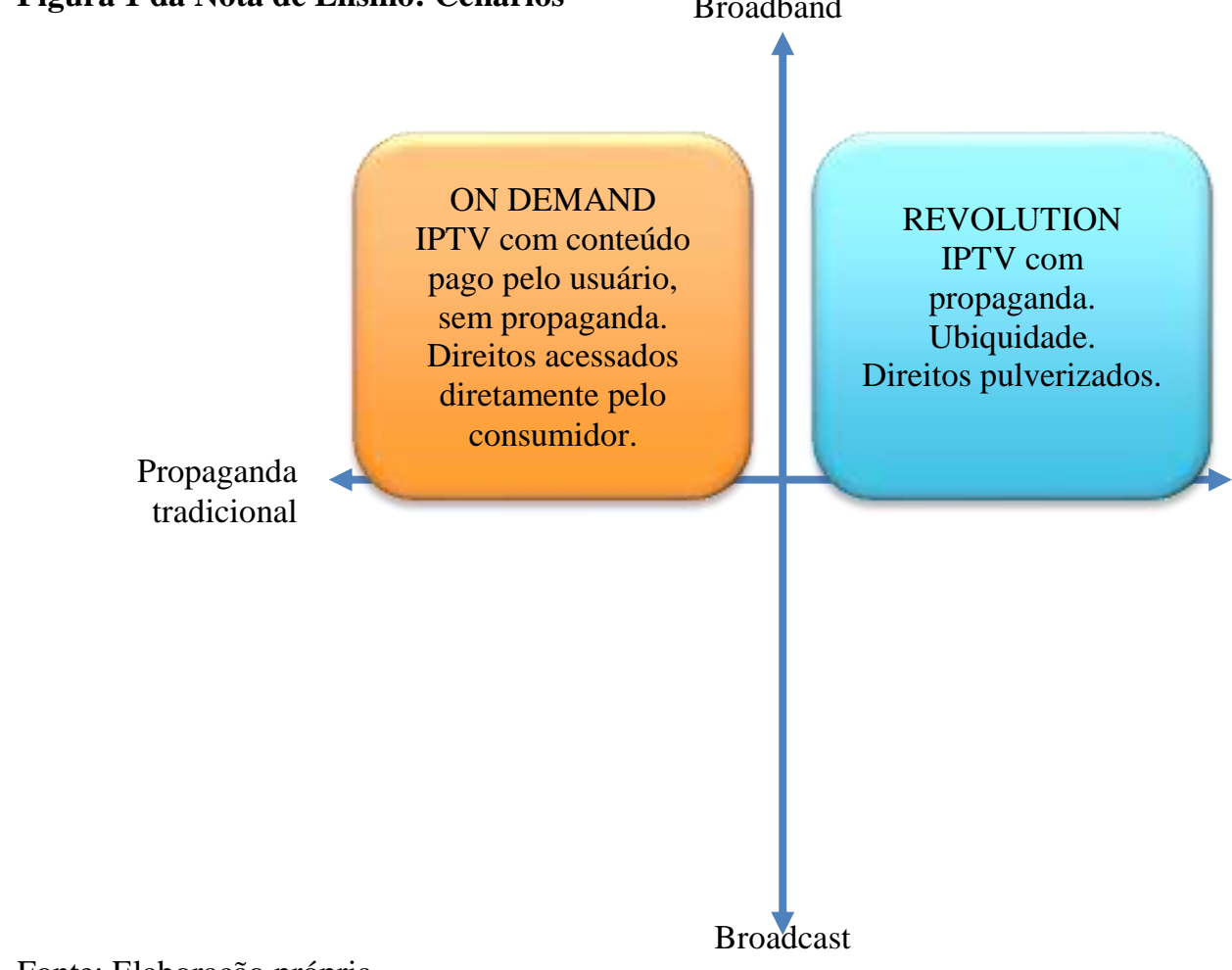

Propaganda personalizada e interat:

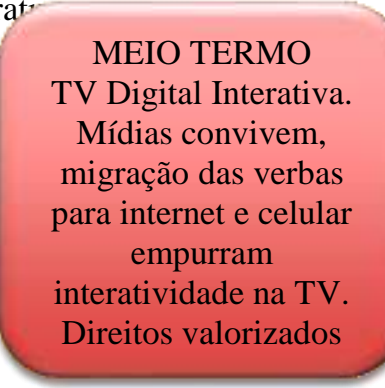

Fonte: Elaboração própria.

O primeiro cenário, denominado Status Quo, representa a situação mais próxima da configuração do mercado atual. As emissoras de TV são predominantemente abertas, sem muito espaço para emissoras especializadas. A grade é construída de forma a segmentar horários, diversificando a programação. A relação entre agências de propaganda e emissoras é intensa, com a veiculação do formato tradicional de propaganda de trinta segundos. Neste cenário, institutos de pesquisa possuem força, já que a audiência é fundamental para a decisão do melhor horário e canal para veicular determinados tipos de anúncio. Os direitos são extremamente valorizados e, em geral, vendidos com exclusividade, dando a seus detentores uma grande vantagem sobre seus principais competidores. Há uma grande concentração em broadcast. Neste cenário, é importante para o Esporte Interativo obter uma licença para transmitir via UHF ou VHF. É 
necessário também ter recursos financeiros e pessoais para montar uma grade completa, ou seja, é preciso crescer ainda mais. Outro ponto fundamental é comprar os direitos de transmissão, visto que são eles que proporcionarão a empresa algum tipo de vantagem sobre seus concorrentes.

No cenário Meio Termo há a coexistência entre novas mídias e mídias tradicionais, cada uma ocupando um espaço diferente, ou seja, há segmentação tanto no tipo de mídia quanto no tipo de conteúdo, com espaço para emissoras de TVs dedicadas a um determinado gênero de programação. A propaganda passa a ser mais segmentada, de acordo com o público de cada emissora. Os direitos continuam valorizados, mas se perde parte da exclusividade, já que eles passam a ser comercializados para diferentes mídias. Outra mudança é o crescimento da interatividade na TV a partir da internet e do celular, e ambos se tornam mais um meio de contato entre consumidores finais e emissoras. O modelo de negócios continua sendo o de subsídio cruzado, e receitas com propaganda em celulares e internet ganham força. Aqui, é necessário estar presente em novas mídias e iniciar processos de CRM dentro da empresa, de forma a dar informações sobre seus consumidores a anunciantes.

No cenário On Demand, o consumidor começa a ter controle sobre a sua programação, com a internet TV ganhando cada vez mais adeptos. O consumidor passa a ter a capacidade de pular propagandas que não são do seu interesse, ameaçando assim o modelo tradicional. A segmentação da televisão se intensifica, com o espectador tendo oportunidade de escolher a oferta que mais se encaixa em seu perfil. O modelo de subsídio cruzado passa a ficar inviável, já que o consumidor prefere pagar por conteúdo sem qualquer tipo de propaganda. Assim, institutos de pesquisa e agências de propaganda perdem força, e as emissoras de TV buscam se segmentar, já que devem oferecer uma solução completa para seus consumidores. Neste cenário, saber o que seu consumidor quer passa a ser a principal diferença entre sucesso e fracasso. Ferramentas de CRM são

\section{Plano para Aplicação do Caso}

Para aplicação do caso em sala de aula é fundamental que os alunos tenham sido orientados sobre o método e suas etapas, e sobre a importância do comprometimento de todos para criar um ambiente favorável à discussão e ao desenvolvimento de argumentos (MauffetteLeenders et al, 1997). Especificamente neste estudo de caso, o professor deve estimular os alunos a se colocar no lugar do protagonista da história, Edgar Diniz, e a buscar compreender todas as questões fundamentais para a sobrevivência. Faz sentido também investir em uma estratégia multicanal, isto é, acompanhar o consumidor por todos os momentos de consumo, dando a ele a oferta completa que ele tanto almeja. Faz-se necessário criar sinergias entre diversas mídias e ações, como transmissões de jogos, elaboração de eventos e até mesmo vendas de artigos que estão presentes nas transmissões, além de ter um conteúdo multiplataforma, isto é, adaptável a qualquer mídia.

O cenário Revolution apresenta as maiores mudanças. Tecnologias como internet TV mudam os hábitos dos consumidores que passam a ter total controle sobre suas grades. Isto quer dizer que cada consumidor faz a sua própria programação, diminuindo o poder dos Institutos de Pesquisa. Além disso, essas tecnologias dão a oportunidade de ignorar comerciais. Com isso, o modelo de subsídio cruzado é comprometido e a principal base de receita das emissoras de TV se inviabiliza. Além disso, a transmissão passa a ser feita de qualquer lugar a qualquer hora, isso quer dizer que é possível ter acesso a conteúdos com qualquer aparelho que tenha uma conexão com a internet. Neste sentido, os direitos de transmissão perdem força, já que estão totalmente pulverizados. A internet se torna o principal canal para transmissão de conteúdo, mas também surge como uma grande oportunidade para um contato direto entre consumidor final e propagadores de conteúdo. No entanto, como os direitos estão pulverizados, é preciso estabelecer algum tipo de fidelidade com o consumidor final. Portanto, é necessário criar valor para o consumidor a partir de uma oferta customizada e até mesmo exclusiva. Neste cenário, é necessário possuir competências de marketing, principalmente aquelas relacionadas a CRM. Além disso, poderiam ser criados sistemas wikis, nos quais o conteúdo fosse criado pelos próprios consumidores. O modelo de negócios se sustentaria a partir de cobranças por conteúdos exclusivos e acesso a áreas restritas.

envolvidas na complexa e dinâmica indústria de mídia. Além da leitura prévia da bibliografia recomendada (presentes nas Referências Bibliográficas), sugere-se que o professor encoraje os alunos a pesquisar notícias sobre o Esporte Interativo, a negociação da empresa com a Turner e os movimentos da indústria de mídia no Brasil.

Seguindo a estrutura do método do caso, recomenda-se o cumprimento de três estágios: (a) leitura e análise individual do caso, complementada 
pelas leituras recomendadas; (b) discussão do caso em pequenos grupos; e (c) discussão em plenária, mediada pelo professor, envolvendo todos os alunos. Sugere-se que a discussão do caso em plenária tenha a duração de 90 minutos, assim distribuídos:

- 10 min: Visão geral da situação: principais aspectos envolvidos no dilema do caso.

- 30 min: Análise da trajetória do Esporte Interativo, e das oportunidades de modelos de negócios para empresa, com ênfase na

\section{REFERÊNCIAS}

ADNER, R. (2006) Match your innovation strategy to your innovation ecosystem. Harvard Business Review, 84(4), pp. 98-107

AGÊNCIA BRASIL (2014). TV por assinatura chega a quase $30 \%$ dos lares brasileiros. Disponível em:

<http://agenciabrasil.ebc.com.br/economia/noticia/2 014-04/tv-por-assinatura-ja-esta-em-28-dos-

domicilios-do-pais>. Acessado em 15 de abril de 2015 .

CHRISTENSEN, C. (1997). The innovator's dilemma: when new technologies cause great firms to fail. Boston: Harvard Business School Press.

CHRISTENSEN, C. M., JOHNSON, M.W., \& RIGBY, D.K. (2002). Foundations for growth: how to identify and build disruptive new businesses. Sloan Management Review, 43(3), pp. 22-31.

DAY, G.; SCHOEMAKER , P. J. (2006). Peripheral Vision: Decteting the Weak Signal that Will Make or Break Your Company. Boston: Harvard Business School Press.

DAY, G.; SCHOEMAKER , P. J.; GUNTHER, R. E. (2000). Wharton on Managing Emerging Technologies.

Hoboken: John Wiley \& Sons, Inc.

EISENMANN, T. R. (2006) Winner-Take-All in Networked Markets. Boston: Harvard Business School Press.

EISENMANN, T. R.; PARKER, G.; VAN ALSTYNE, M. (2006). Strategies for Two-Sided Markets, Harvard Business Review, 84, n. 10.

GARVIN, D.A.; LEVESQUE, L.C. (2005) $A$ note on scenario planning. Harvard business school note 9-306-003. complexidade do Ecossistema no qual a empresa está inserida e nas oportunidades de Inovação apresentadas.

- 30 min: Construção e análise de possíveis cenários, considerando a dinâmica da indústria em que a empresa está inserida.

- 20 min: Com base nas análises anteriores, elaboração de recomendações para o dilema de Edgar Diniz.

IANSITI, M.; LEVIEN, R (2004) Strategy as Ecology, Harvard Business Review; 82, pp. 6878 .

ISABELLA, L. (1990). Evolving Interpretations as a Change Unfolds: How Managers Construe Key Organizational Events. Academy of Management Journal, 33(1), pp. 7-41.

IYER, B.; LEE, C.; VENKATRAMAN, N. (2006). Managing in a "Small World Ecosystem": Lessons from The Software Sector. California Management Review, 48 (3), pp. 28-47.

MAUFFETTE-LEENDERS, L.A.; ERSKINE, J.A.; LEENDERS, M.R. (1997). Learning with Cases. London, Canada: Research and Publications Division, School of Business Administration, University of Western Ontario.

MEDIA BOOK (2012). Hábitos de Mídia e Investimento Publicitário em 2011. Disponível em: $<$ http://www4.ibope.com.br/ibope_media/2012/med iabook/pt/>. Acessado em 15 de abril de 2015.

PROJETOS INTERMEIOS (2014). Relatório de Investimentos em Média Consolidado. Disponível em: <http://www.projetointermeios.com.br/relatoriosde-investimento>. Acessado em 15 de abril de 2015.

PROJETOS INTERMEIOS (2011). Relatório de Investimentos em Média Consolidado. Disponível em: $<$ http://www.projetointermeios.com.br/relatoriosde-investimento>. Acessado em 15 de abril de 2015.

ROESCH, S. (2006). Notas sobre a Construção de Casos para Ensino. Anais do XXX Encontro Nacional da ANPAD. Salvador: ANPAD. 
GIL, A. (1999) Métodos e Técnicas de Pesquisa Social, 5a Edição. São Paulo: Atlas.

ROGERS, E. M. (1995). Diffusion of Innovations. New York: Free Press.
SCHOEMAKER, P. J. (1995). Scenario Planning: A Tool for Strategic Thinking. Sloan Management Review, 36(2), pp. 25-40.

\footnotetext{
i O hino da Liga dos Campeões é uma adaptação feita por Britten da música "Zadok the Priest”, de Handel. O hino é cantado em inglês, alemão e francês, pois são os idiomas oficiais da UEFA.

ii Empresa norte-americana que oferece serviço de TV por Internet em mais de 40 países. Pagando uma mensalidade menor que 10 dólares, o assinante pode assistir a um número ilimitado de filmes e séries, quando e onde quiser, em praticamente qualquer tela com conexão à Internet, sem intervalos comerciais.

iii Sigla para Short Message Service, que significa Serviço de Mensagens Curtas - trata-se de um serviço para o envio de mensagens de texto curtos, através de telefones celulares.

iv Sistema que possibilita que as pessoas assistam aos programas que desejarem na hora em que preferirem.

v Conjunto de veículos e aparelhos de comunicação baseados em tecnologia digital.

vi Programas que se pode instalar no telefone celular.

vii O subsídio cruzado prevê que o conteúdo ou serviço entregue ao consumidor é gratuito para o mesmo, posto que sua produção e distribuição são financiadas pela venda de espaço publicitário adquirido por anunciantes.

viii Dispositivos com sistema operacional que permite que a realização de várias tarefas simultâneas.
} 